\title{
Systemic sclerosis: a prototypic multisystem fibrotic disorder
}

\author{
John Varga' and David Abraham²
}

${ }^{1}$ Feinberg School of Medicine, Northwestern University, Chicago, Illinois, USA. ${ }^{2}$ Centre for Rheumatology, University College London, London, United Kingdom.

\begin{abstract}
A unique feature of systemic sclerosis (SSc) that distinguishes it from other fibrotic disorders is that autoimmunity and vasculopathy characteristically precede fibrosis. Moreover, fibrosis in SSc is not restricted to a single organ, but rather affects many organs and accounts for much of the morbidity and mortality associated with this disease. Although immunomodulatory drugs have been used extensively in the treatment of SSc, no therapy to date has been able to reverse or slow the progression of tissue fibrosis or substantially modify the natural progression of the disease. In this Review, we highlight recent studies that shed light on the cellular and molecular mechanisms underlying the fibrotic process in SSc and that identify cellular processes and intra- and extracellular proteins as potential novel targets for therapy in this prototypic multisystemic fibrotic disease.
\end{abstract}

\section{Clinical overview}

Systemic sclerosis (SSc) is a connective tissue disease of unknown etiology that is highly heterogeneous in its multisystem clinical manifestations and follows a variable and unpredictable course. The hallmarks of SSc are autoimmunity and inflammation, widespread vasculopathy (blood vessel damage) affecting multiple vascular beds, and progressive interstitial and perivascular fibrosis (1). This constellation of seemingly disparate yet interlinked features differentiates SSc from other connective tissue diseases and organspecific fibrosing disorders. Patients with SSc are commonly classified into two distinct subsets on the basis of the pattern of skin involvement. Diffuse cutaneous SSc, the focus of this Review, is dominated by rapidly progressive fibrosis of the skin, lungs, and other internal organs (2). By contrast, limited cutaneous SSc is dominated by vascular manifestations, and skin and organ fibrosis is generally limited and slow to progress. Although clinical outcomes have improved considerably, presumably due to better management of the complications, SSc is still considered incurable, and the diffuse cutaneous form carries the highest risk of fatality of the connective tissue diseases, with $55 \%$ survival at 10 years (3).

$\mathrm{SSc}$ has a worldwide distribution and is more frequent in women than men. Based on incidence and survival rates, an estimated $75,000-100,000$ individuals in the United States have SSc (3). The genetics of SSc are complex, and although the disease is inherited, it is not inherited in a Mendelian fashion. Twins show a low disease concordance rate $(<5 \%)$ that is similar between monozygotic and dizygotic twin pairs (4). SSc occurs substantially more frequently in families (1.6\%) than in the general population $(0.026 \%)$, and a positive family history represents the strongest risk factor for SSc yet identified (5). The etiology of SSc is unknown. Viruses, including human CMV, have been implicated as potential causative agents (6), along with drugs and environmental and occupational exposures to organic solvents, vinyl chloride, and silica (7). Antibodies specific for human CMV can frequently be detect-

Nonstandard abbreviations used: CTGF, connective tissue growth factor; CXCR4, CXC chemokine receptor 4; EMT, epithelial-mesenchymal transition; ET-1, endothelin 1; FAK, focal adhesion kinase; MCP-1, monocyte chemoattractant protein 1 ; p300/CBP, p300/CREB-binding protein; SBE, SMAD-binding element; SSc, systemic sclerosis; TGF $\beta$ RII, TGF- $\beta$ receptor type II; Tsk1/+, tight skin 1.

Conflict of interest: The authors have declared that no conflict of interest exists. Citation for this article: $J$. Clin. Invest. 117:557-567 (2007). doi:10.1172/JCI31139. ed in patients with SSc $(8,9)$. Some of these antibodies induce endothelial cell apoptosis and fibroblast activation in cell culture assays, suggesting that they have a direct pathogenic role in tissue damage (10). Furthermore, infection with human CMV is associated with enhanced production of connective tissue growth factor (CTGF), which can drive fibroblast activation and is implicated in pathological fibrosis (11).

\section{Animal models}

The pathogenesis of SSc involves a distinctive triad of small-vessel vasculopathy, inflammation and autoimmunity, and interstitial and vascular fibrosis in the skin, lungs, and multiple other organs (1). Various animal models have been investigated as spontaneous or inducible models for SSc. Although none of them reproduce all three pathogenetic components of the disease, some models do recapitulate selected phenotypic features (Table 1 ). The tight skin $(T s k 1 /+)$ mouse is characterized by diffuse thickening and tethering of the skin (12). Although mice homozygous for the Tsk1 mutation die in utero at 8-10 days of gestation, heterozygous (Tsk1/+) mice are viable, and develop tight skin that is firmly bound to the underlying subcutaneous tissue. In contrast to human SSc, which is characterized by thickening and sclerosis of the dermis, Tsk1/+ mice manifest hyperplasia of the subcutaneous tissue but the dermis is unaffected (13). Furthermore, Tsk1/+ mice develop emphysema-like changes in the lungs rather than fibrosis, and vasculopathy does not occur. The Tsk1 mutation is a tandem duplication in the gene encoding fibrillin-1 (14), a microfibrillar connective tissue protein; mutation of the gene encoding fibrillin- 1 is also implicated in Marfan syndrome, an inherited connective tissue disorder affecting the skin, ligaments, major arteries, and heart valves, but not associated with fibrosis (14). Although the mechanisms linking the Tsk1 mutation to the fibrotic skin phenotype are currently not known, it is noteworthy that the mutation in the gene encoding fibrillin- 1 in Marfan syndrome is associated with increased signaling by TGF- $\beta$, and that the mouse Marfan phenotype can be reversed by inhibiting TGF- $\beta$ signaling (15). Because fibrillin- 1 mediates the bioavailability of TGF- $\beta$ by direct binding, or by interactions with latent TGF- $\beta$ binding proteins (16), it has been suggested that the Tsk1 mouse phenotype represents tissue fibrosis due to deregulated TGF- $\beta$ activation and enhanced profibrotic signaling by this cytokine. 
Table 1

Mouse models of SSc

\begin{tabular}{|c|c|c|c|c|c|}
\hline \multirow[t]{2}{*}{ Model } & \multicolumn{4}{|c|}{ Reproduces key features of SSc } & \multirow[t]{2}{*}{ Further details } \\
\hline & Vasculopathy & Inflammation & Autoimmunity & Fibrosis & \\
\hline \multicolumn{6}{|l|}{$\begin{array}{l}\text { Naturally occurring, } \\
\text { spontaneous }\end{array}$} \\
\hline Tsk1/+ & - & - & + & + & $\begin{array}{l}\text { Mutation in the gene encoding fibrillin-1. Skin } \\
\text { tethering, subcutaneous hyperplasia. No lung } \\
\text { or renal fibrosis. }\end{array}$ \\
\hline Tsk2 & - & + & + & + & $\begin{array}{l}\text { Unknown genetic defect. Early cutaneous } \\
\text { inflammatory cell infiltrate. No lung or renal } \\
\text { fibrosis. }\end{array}$ \\
\hline \multicolumn{6}{|l|}{ Induced } \\
\hline Bleomycin & - & + & - & + & $\begin{array}{l}\text { Subcutaneous injection of bleomycin induces } \\
\text { fibrosis in skin, lungs, and kidneys. }\end{array}$ \\
\hline GVHD I & + & + & - & + & $\begin{array}{l}\text { Transfer of spleen cells from wild-type B10.D2 } \\
\text { mice into irradiated Balb/c mice results in skin } \\
\text { and lung fibrosis. }\end{array}$ \\
\hline GVHD ॥ & + & + & + & + & $\begin{array}{l}\text { Transfer of spleen cells from wild-type B10.D2 } \\
\text { mice into RAG2-deficient mice results in skin } \\
\text { and lung fibrosis. }\end{array}$ \\
\hline \multicolumn{6}{|l|}{ Transgenic } \\
\hline DN TGF $\beta$ RII & - & + & - & + & Mice transgenic for a DN TGF $\beta$ RII. \\
\hline Conditional TGF $\beta$ RI & + & + & - & + & $\begin{array}{l}\text { Fibroblast-restricted conditional transgenic } \\
\text { expression of TGF } \beta \mathrm{RI} \text {. }\end{array}$ \\
\hline
\end{tabular}

DN, dominant-negative; GVHD, graft-versus-host disease; +, present; -, absent.

Fibrosis can be induced in mice by subcutaneous injection of bleomycin (17). In this mouse model, the sequence of histopathological changes in the skin closely resembles that seen in SSc - early mononuclear cell accumulation and upregulated TGF- $\beta$ and chemokine expression followed by dermal fibrosis with accumulation of $\alpha$-SMA-expressing myofibroblasts $(18,19)$. The mice also manifest evidence of pulmonary and renal fibrosis. In light of its reproducibility, relative strain independence, and ease of induction, the subcutaneous bleomycin model is used with increasing frequency to investigate the roles of specific gene products in SSclike disease $(19,20)$. Transplantation of MHC-mismatched BM or spleen cells into sublethally irradiated recipient mice results in an SSc-like condition resembling chronic graft-versus-host disease, with skin and lung fibrosis accompanied by evidence of autoimmunity $(21,22)$. Recently, various mouse strains with genetic modifications resulting in SSc-like phenotypes have been created. For example, mice lacking the genes encoding relaxin (23), caveolin (24), THY-1 (25), or FLI-1 (26) and transgenic mice expressing a mutant TGF- $\beta$ receptor type II (TGF $\beta$ RII) in fibroblasts (27) spontaneously manifest certain fibrotic or vascular features of SSc or show enhanced sensitivity to fibrosis induced by bleomycin. These transgenic and knockout mice provide robust novel experimental tools for advancing SSc research.

\section{Pathogenesis: an integrated view of vascular damage and autoimmunity culminating in organ fibrosis}

The pathogenesis of SSc involves interplay between obliterative vasculopathy in multiple vascular beds, inflammation and autoimmunity, and progressive fibrosis (Figure 1). Vascular injury and activation are the earliest and possibly primary events in the pathogenesis of SSc (28). Histopathological evidence of vascular damage is present before fibrosis, and clinical manifestations such as Raynaud phenomenon, an episodic and reversible cold-induced vasospasm of the fingers and toes, precede other disease manifestations. Additional manifestations of SSc-associated vasculopathy include cutaneous telangiectasia, nail fold capillary alterations, pulmonary arterial hypertension, gastric antral vascular ectasia, and scleroderma renal crisis with malignant hypertension (29). In late-stage SSc, there is a striking paucity of small blood vessels in lesional skin and other organs. Endothelial cell injury might be triggered by granzymes, endothelial cell-specific autoantibodies, vasculotropic viruses, inflammatory cytokines, or reactive oxygen radicals generated during ischemia/reperfusion (29).

Injury causes endothelial cell activation and dysfunction, altered capillary permeability, increased expression of VCAM-1 and endothelial leukocyte adhesion molecule 1, altered secretion of vasoactive mediators, and activation of platelets and fibrinolytic pathways (30). Activated endothelial cells release endothelin-1 (ET-1), a potent vasoconstrictor that also promotes leukocyte adhesion to the endothelium as well as vascular smooth muscle cell proliferation and fibroblast activation. Levels of ET-1 are elevated in the blood and in bronchoalveolar lavage fluids from patients with $\operatorname{SSc}(31,32)$. Microvascular injury and damage lead to vascular remodeling, with hypertrophy of the intimal and medial layers and adventitial fibrosis resulting in progressive luminal narrowing and obliteration (33). Combined with endothelial cell apoptosis, the process culminates in a striking absence of blood vessels visible on angiograms of SSc patients with late-stage disease. Loss of microvasculature is associated with tissue hypoxia, which normally induces strong expression of VEGF and its receptors (34, 35). An apparent paradox is that, in the face of tissue hypoxia and ongoing angiogenic drive, SSc is associated with a lack of angiogenesis and progressive disappearance of blood vessels. Recent studies indicate that the failure in vasculogenesis is due to a reduc- 


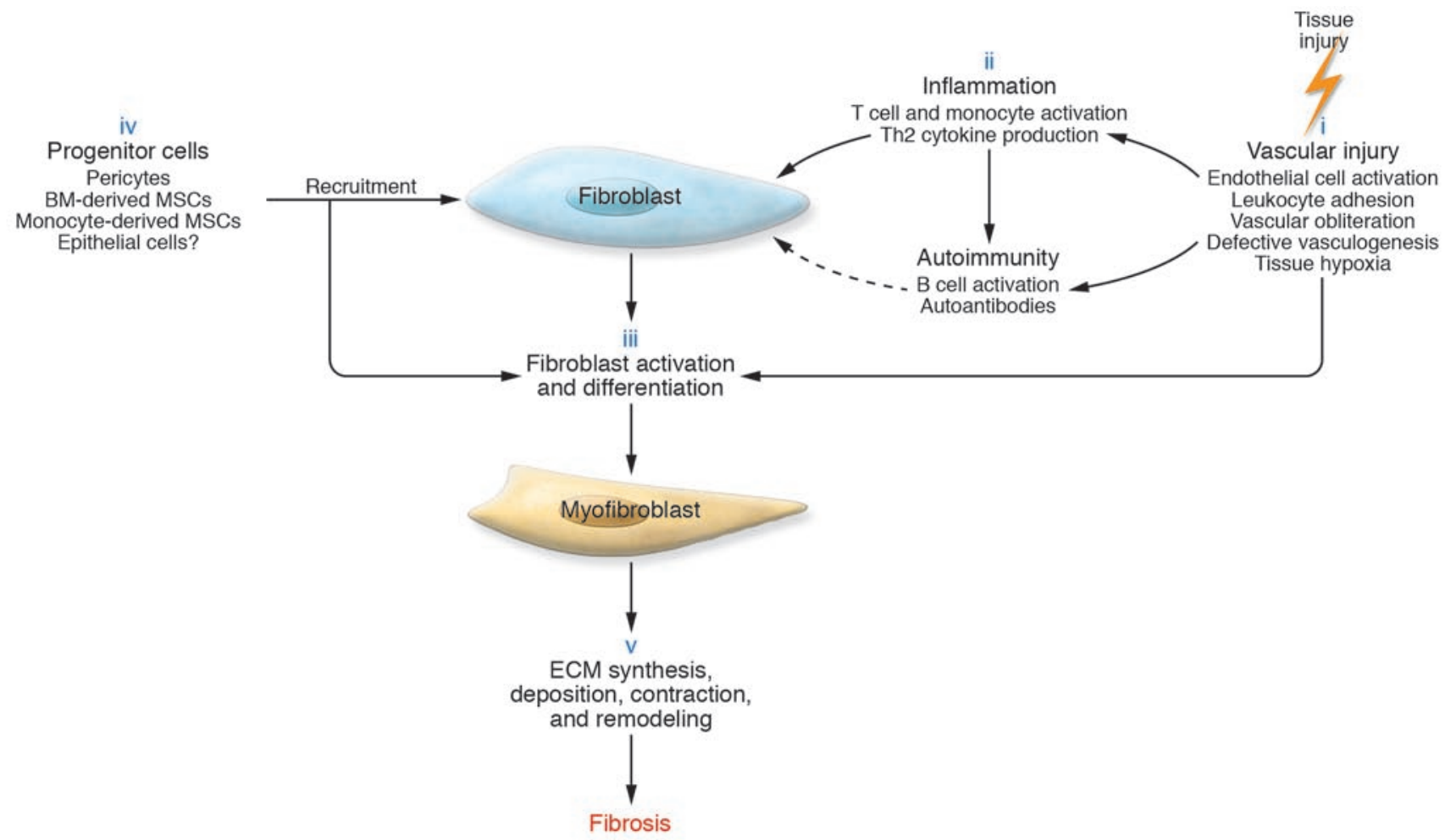

Figure 1

Pathogenesis of SSc: integration of vasculopathic and immunological processes leading to fibrosis. The pathogenesis of SSc is initiated by microvascular injury (i). This induces inflammation and autoimmunity (ii), which have direct and indirect roles in inducing fibroblast activation (iii), a key event in the development of fibrosis. The number of fibroblasts and their precursors in affected tissues is increased by trafficking as well as by the differentiation of mesenchymal cells (iv). Activated myofibroblasts in the lesional tissue perform a series of functions culminating in fibrosis (v). MSC, mesenchymal stem cell.

tion in BM-derived $\mathrm{CD} 34^{+}$circulating endothelial progenitor cells as well as their impaired differentiation into mature endothelial cells $(36,37)$. Whether the reduction in circulating endothelial progenitor cells in SSc is due to "exhaustion" of the BM, destruction of progenitor cells in the peripheral circulation, or some other mechanism(s) remains unresolved.

The innate and the adaptive immune systems both have a role in the pathogenesis of SSc (1). In patients with early-stage disease, leukocyte activation is evident in lesional tissues as well as in the peripheral blood and has a direct role in tissue injury. Perivascular infiltrates are predominantly $\mathrm{CD}^{+}$and $\mathrm{CD} 4^{+}$mononuclear cells that express the activation markers CD45, HLA-DR, and the IL-2 receptor and secrete fibrogenic cytokines and chemokines (38). Lesional $\mathrm{T}$ cells have restricted receptor specificities indicative of oligoclonal $\mathrm{T}$ cell expansion (39); however, it is not known whether these clones are activated nonspecifically (by cytokines or chemokines) or specifically (by unknown antigens). An emerging hypothesis for the pathogenesis of fibrotic disorders implicates an altered balance between Th1 and Th 2 cytokines (40). T cells polarized toward a Th2 cell phenotype secrete abundant IL-4, IL-5, and IL-13 and demonstrate a paucity of the hallmark Th1 cytokine IFN- $\gamma$ (40). Animal studies provide support for the role of a polarized immune response in the pathogenesis of fibrosis. For example, Th2-polarized cells can induce fibrosis when passively transferred in vivo (41), and mice lacking the Th1-specific transcription factor T-bet show exaggerated skin fibrosis in response to bleomycin (42). Patients with SSc display a relative shift in the Th1-Th2 cytokine balance toward Th2 predominance. As assessed by DNA microarray analysis, peripheral blood leukocytes from patients with SSc show elevated GATA3, which drives Th2 polarization (43), and $\mathrm{CD}^{+} \mathrm{T}$ cell clones from SSc skin biopsies show a Th2 cytokine profile (44). Furthermore, alveolar CD8 ${ }^{+}$cells show elevated production of Th2 cytokines, and the Th2 predominance predicts accelerated decline in lung function (45). In addition, proteomic analysis confirms the predominant Th2 cytokine profile in SSc bronchoalveolar lavage fluids (46).

Highly specific autoantibodies can be detected in the serum in virtually all patients with SSc. These autoantibodies also show strong association with individual disease phenotypes, and their levels fluctuate with disease activity (47). Mechanisms invoked to explain autoantibody generation in patients with SSc include molecular mimicry, chronic B cell hyperreactivity due to intrinsic B cell abnormalities, and increased expression or altered subcellular localization of potential autoantigenic peptides (48). Although SSc-associated autoantibodies have clinical utility as diagnostic markers, their contributions to disease manifestations remain uncertain. Recent studies highlight the biological activities and potential pathogenic roles of autoantibodies in patients with SSc, suggesting that antibodies specific for fibroblasts, endothelial cells, and PDGF receptors might directly cause fibroblast or endothelial cell activation and contribute to tissue damage. For example, endothelial cell-specific antibodies in SSc induce adhe- 

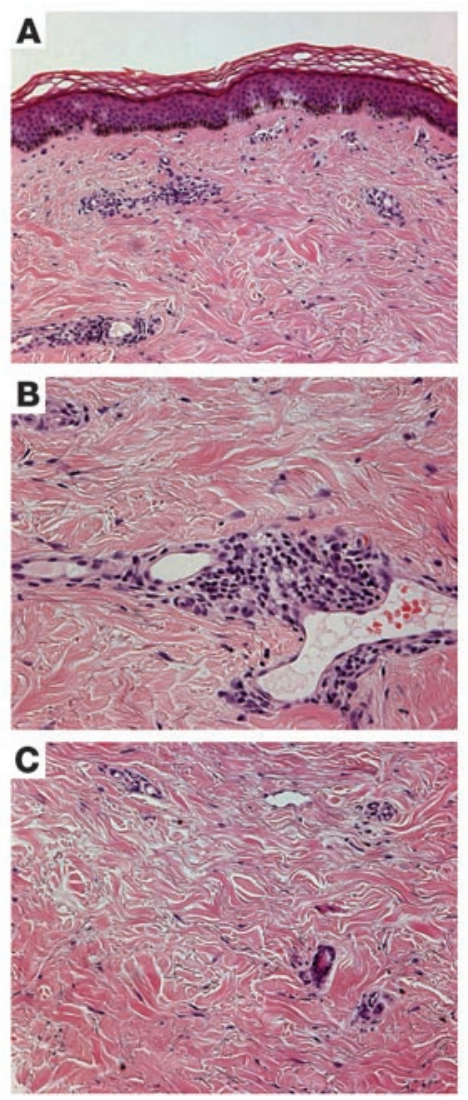

sion molecule expression on endothelial cells, and antibodies specific for the PDGF receptor seem to stimulate expression of the genes encoding collagen in fibroblasts (49-51).

Although B cells are not generally prominent in lesional tissue, an activated B cell signature has been demonstrated by DNA microarray analysis in SSc skin (52). Furthermore, circulating memory B cells are chronically activated and express increased levels of CD95 and CD19, a cell surface signaling receptor that regulates $\mathrm{B}$ cell responses (53). Transgenic mice overexpressing CD19 spontaneously develop high titers of topoisomerase I-specific antibodies characteristically associated with SSc, although they do not develop clinical features of the disease (54). Depletion of $\mathrm{B}$ cells resulted in amelioration of skin fibrosis in the Tsk1/+ mouse, suggesting that B cells have an as yet undefined role in the pathogenesis of fibrosis associated with the fibrillin-1 mutation (55). Altered B cell function in SSc might account not only for autoantibody production but also for fibrosis, since activated B cells secrete IL-6, which directly stimulates fibroblasts (55). Patients with SSc also have elevated levels of B cell-activating factor (BAFF) in the serum and in lesional skin, and B cells express increased levels of BAFF receptor (56).

\section{Fibrosis in SSc}

Overview: molecular and cellular determinants of the ECM. Fibrosis is the most characteristic pathological hallmark of SSc, and it is especially prominent in the diffuse cutaneous form of the disease (Figure 2; ref. 57). Progressive replacement of tissue architecture by collagen-rich ECM results in functional impairment of affected organs. The fibrotic process is most prominent in the skin, lungs,

\section{Figure 2}

Skin inflammation and fibrosis in SSc. (A) In early diffuse cutaneous SSc, moderate fibrosis in the upper dermis and at the dermal-epidermal junction is accompanied by evidence of keratinocyte hypertrophy with a flattening of the epidermis, leading to loss of reticular structure and decreased length of rete pegs (fingerlike structures that project up from the dermis and down from the epidermis, increasing the area of contact between the layers of the skin). In addition, inflammatory infiltrates are found in the dermis and near the dermal-epidermal junction, predominantly around small blood vessels. (B) Early-stage diffuse disease showing profound dermal inflammation characterized by perivascular mononuclear cellular infiltrate composed of monocytes and activated lymphocytes, with perivascular fibrosis and loss of pericytes and vessel integrity. (C) In established fibrosis, collagen accumulation leads to dermal thickening and the deposition of dense and closely packed collagen fibers throughout the dermis, with the loss of the microvasculature and dermal structures and the dermis-subcutaneous adipose tissue interface. All images are stained with H\&E and photographed using a Zeiss Axioscope confocal microscope under light field. Original magnification, $\times 100(\mathbf{A}$ and $\mathbf{C}) ; \times 200$ (B).

gastrointestinal tract, heart, tendons and ligaments, and endocrine glands; widespread perivascular fibrosis also occurs. Fibrotic damage to these affected organs accounts for much of the morbidity and mortality associated with SSc. The ECM consists of a cellular compartment of resident and infiltrating cells and a connective tissue compartment composed of collagens, proteoglycans, fibrillins, and adhesion molecules (58). The ECM also functions as a reservoir for TGF- $\beta$, CTGF, and other growth factors and matricellular proteins that, together with the connective tissue compartment, control mesenchymal cell differentiation, function, and survival. Excessive connective tissue accumulation is due to overproduction by fibroblasts and related mesenchymal cells activated by soluble factors in an autocrine and/or paracrine manner, or by cell-cell or cell-ECM interactions. Impaired ECM degradation and turnover and expansion of the pool of mesenchymal cells in lesional tissues further contribute to ECM accumulation (58).

The most abundant ECM components are collagens, a family of proteins that consists of over two dozen structural proteins with critical roles in organ development, growth, and differentiation. The genes encoding the various collagen proteins harbor conserved regulatory elements that are specifically recognized by DNA-binding transcription factors. The complement of generalized and tissue-specific transcription factors implicated in regulating the expression of the genes encoding collagen proteins includes SP1, SMAD3, ETS1, early growth response 1, and CCAAT-binding factor, which mediate stimulation, and SP3, CCAAT/enhancer binding protein, Y box-binding protein 1, c-KROX, and FLI-1, which suppress transcription (59). These transcription factors not only interact with one another but also with cofactors and chromatin-modifying enzymes such as p300/ CREB-binding protein (p300/CBP), p300/CBP-associated factor, and histone deacetylases that are recruited to target genes by DNA-bound transcription factors. The relative levels, intracellular activities, and interactions among transcription factors and cofactors are controlled by extracellular cues, and alterations in these contribute to persistent fibroblast activation in SSc (60).

Cellular determinants of fibrosis: fibroblasts, myofibroblasts, pericytes, and transdifferentiation. Fibroblasts are key effectors of the fibrotic process. Soluble mediators generated in the local cellular microenvironment by platelets, endothelial cells, epithelial cells, and 


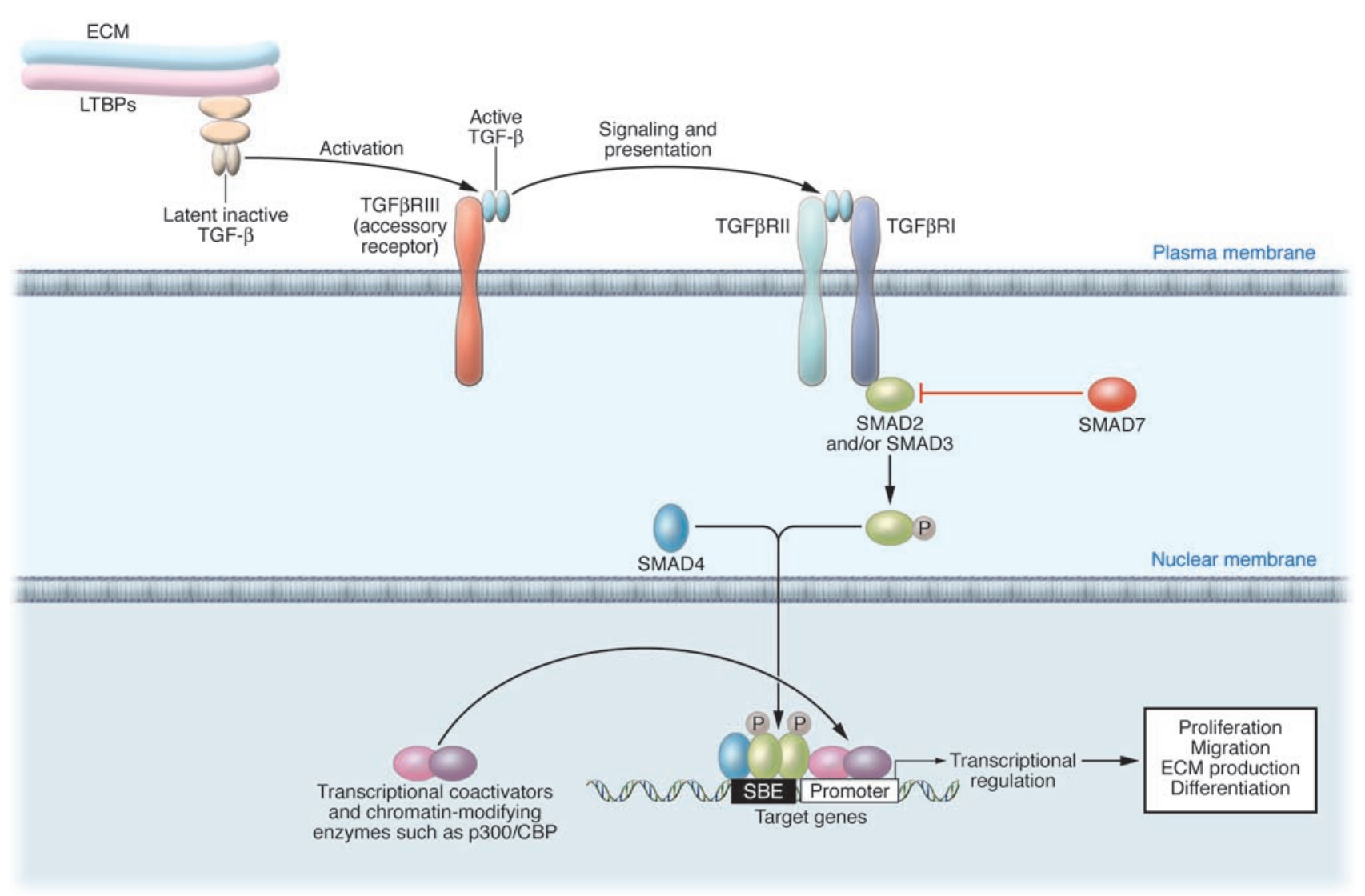

Figure 3

Profibrotic signaling by TGF- $\beta$ through SMAD-dependent pathways. The ECM serves as a reservoir for latent TGF- $\beta$, which is maintained in an inactive form by latent TGF- $\beta$ binding proteins (LTBPs). Upon activation, TGF- $\beta$ binds to its cell surface receptors and triggers SMAD-mediated intracellular signal transduction. Activated SMAD proteins accumulate in the nucleus and bind to conserved SBE regulatory elements in target genes, recruit coactivators and chromatin-modifying enzymes such as p300/CBP to the DNA, and induce mRNA synthesis and cellular responses. Inhibitory SMAD7 blocks ligand-induced SMAD protein phosphorylation and shuts down SMAD-mediated signaling.

inflammatory cells provide cues that induce fibroblasts to secrete collagens and other ECM macromolecules to adhere to, contract, organize, and remodel connective tissue; to secrete and activate growth factors and cytokines; and to undergo transdifferentiation into contractile myofibroblasts (61). Together, these biosynthetic, contractile, and adhesive functions enable fibroblasts to mediate effective wound healing. Under normal circumstances, the fibroblast repair program is self limited, but pathological fibrotic responses are characterized by sustained and amplified fibroblast activation. Inappropriate fibroblast activation is the fundamental pathogenetic alteration underlying fibrosis in SSc. Recent DNA microarray studies have revealed that fibroblasts from different anatomic locations differ markedly in their gene expression patterns and show site-specific variations in their transcriptional profiles that seem to be related to their location within the body (62). Moreover, these variations in gene expression are retained and might be considered the "positional memory" of these fibroblasts (62). It will be important to investigate how alterations in fibroblast positional memory might contribute to inappropriate fibroblast activation and fibrosis.

The tissue pool of biosynthetically activated mesenchymal cells contributing to ECM accumulation and remodeling is expanded in fibrosis by proliferation and migration of resident fibroblasts, by in situ transdifferentiation of other cell types, and by the influx of mesenchymal progenitor cells from the circulation (Figure 1; ref. 1). Myofibroblasts are specialized fibroblasts that show features of smooth muscle cell differentiation, having prominent cytoplasmic stress fibers with $\alpha$-SMA. Myofibroblasts synthesize collagens and other ECM components and are a major source of TGF- $\beta$ during the fibrotic response (61). In normal wound healing, myofibroblasts can be detected transiently in the granulation tissue; their removal by apoptosis is a crucial step in wound resolution (63). By contrast, myofibroblasts persist in pathological fibrogenesis, resulting in excessively contracted ECM characteristic of chronic scar (63). Myofibroblast transdifferentiation from normal fibroblasts can be induced by TGF- $\beta$ and requires coexpression of the extra domain A (ED-A) variant form of fibronectin. The presence of $\alpha-\mathrm{SMA}^{+}$myofibroblasts expressing ED-A fibronectin and THY-1 is strongly associated with SSc but is absent from normal skin $(64,65)$. Pericytes are smooth muscle-like structural cells that are found normally in the walls of small blood vessels and have key roles in microvascular integrity and function (66). In earlystage SSc, pericytes are activated and express receptors for PDGF and THY-1, all of which are features of wound healing (65). Under certain conditions, epithelial cells can undergo transformation to fibroblasts (67). Epithelial-mesenchymal transition (EMT) has 


\begin{tabular}{ll}
$\begin{array}{l}\text { Table } 2 \\
\text { Intracellular signaling molecules and pathways deregulated in } \\
\text { SSc fibroblasts }\end{array}$ \\
\hline \\
Molecule & Alteration in SSc fibroblast \\
Transcription factor/cofactor & \\
SMAD2/3 & Constitutive nuclear accumulation \\
& and phosphorylation \\
SMAD7 & Reduced expression and/or function \\
SP1 & Constitutive phosphorylation \\
FLI-1 & Reduced expression \\
p300/CBP & Elevated expression, constitutive \\
& binding to SMAD2/3 \\
PPAR $\gamma$ & Reduced expression \\
Surface receptors & \\
TGF- $\beta$ receptors & Elevated expression of TGF $\beta$ RI \\
& and/or TGF $\beta$ RII; altered ratio \\
PDGF receptors & of TGF $\beta$ RI and TGF $\beta R$ RII \\
Integrin $\alpha_{v} \beta_{5}$ & Both PDGFR- $\alpha$ and PDGFR- $\beta$ elevated \\
Integrin $\alpha_{v} \beta_{3}$ & Elevated \\
Kinases & Elevated \\
PKC- $\delta$ & \\
ERK & Elevated \\
FAK1 & Constitutively active \\
& Constitutively active \\
\hline & \\
\hline &
\end{tabular}

a vital role during embryonic development. The process of EMT can be induced by TGF- $\beta$ in cultured alveolar epithelial cells and suppressed by bone morphogenetic protein-7. Pathological EMT has been documented in cancer as well as in renal and pulmonary fibrosis. To date, the role of EMT in the pathogenesis of tissue fibrosis in SSc has not been examined.

The BM can serve as a source of fibroblast progenitors. Circulating BM-derived mesenchymal progenitors continuously replenish the resident fibroblast population as part of normal tissue homeostasis and might have a role in fibrosis (61). Fibrocytes are $\mathrm{CD} 34^{+} \mathrm{BM}$-derived precursors normally present in small numbers in the peripheral blood (68). Fibrocytes synthesize collagen and express CD14 (a monocyte marker) as well as chemokine receptors CC chemokine receptor 3 (CCR3), CCR5, and CXC chemokine receptor 4 (CXCR4). The cell surface expression of chemokine receptors allows fibrocytes to respond to chemokine gradients and to traffic to and accumulate in specific tissues. Stromal cell-derived factor-1 (SDF-1, also known as CXCL12) is an important chemokine regulator of progenitor trafficking, and its expression, as well as that of its receptor, CXCR4, is elevated in lesional skin in early SSc (69). The pathogenic role for fibrocyte trafficking into lesional tissue has been established in animal models using neutralizing antibodies and in mice genetically deficient in CXCR4 (70). Other studies have identified multipotent monocyte-derived mesenchymal progenitors in peripheral blood (71). The roles of pericytes, fibrocytes, and other monocyte-derived circulating fibroblast progenitors in the pathogenesis of fibrosis in SSc remain to be fully elucidated.

Molecular determinants of fibrosis: TGF- $\beta$. The expression of ECM genes is normally tightly regulated by paracrine and/or autocrine actions of soluble mediators as well as by cell-cell contact, hypoxia, and contact with the surrounding ECM (59). Of the multiple cytokines implicated in SSc, TGF- $\beta$ is considered to be the master regulator of both physiological (wound healing and tissue repair) and pathological (scar) fibrogenesis (60). In addition, TGF- $\beta$ has essential roles in normal tissue repair, angiogenesis, immune regulation, cell proliferation, and cell differentiation (72). TGF- $\beta$ is secreted by platelets, monocytes/macrophages, $\mathrm{T}$ cells, and fibroblasts. Most cell types express specific cell surface receptors for TGF- $\beta$ and secrete TGF- $\beta$ as a latent complex that is sequestered in the ECM, in part by an interaction with fibrillin-1 (73). Activation of latent TGF- $\beta$ to its biologically active form capable of inducing cellular responses can be mediated by integrins, thrombospondins, THY-1, or plasmin (72).

The responses elicited by TGF- $\beta$ are context dependent and specific for target cell lineage. In mesenchymal cells, TGF- $\beta$ functions as a potent fibrogenic stimulus by enhancing collagen synthesis, proliferation, migration, adhesion, and transdifferentiation into myofibroblasts (72). Binding of TGF- $\beta$ to the TGF $\beta$ RII triggers an intracellular signal transduction cascade that leads to the induction of target genes (74). The evolutionarily conserved canonical TGF- $\beta$ signal transduction pathway involves phosphorylation of TGF $\beta$ RI (also known as ALK5), a transmembrane serine-threonine kinase that in turn phosphorylates SMAD proteins (Figure 3). Ligand-induced phosphorylation of SMAD2 and SMAD3 allows them to form heterocomplexes with SMAD4 and translocate from the cytoplasm into the nucleus, where they recognize and bind to a cis-acting DNA sequence (CAGAC) that defines the consensus SMAD-binding element (SBE). Upon SBE binding, activated SMAD proteins recruit transcriptional cofactors to the DNA, resulting in gene transcription. The conserved $\mathrm{SBE}$ is found in the promoters of many TGF- $\beta$-inducible genes, including type I collagen, plasminogen activator inhibitor-1, $\alpha$-SMA, and CTGF. Ligand-induced signal transduction through the SMAD proteins is tightly controlled by endogenous inhibitors such as SMAD7. Deregulated expression or function of activating and inhibitory SMAD proteins and their cofactors has been documented in SSc fibroblasts $(1,58,60)$ and might contribute to the initiation or propagation of the abnormal fibrogenic response (Table 2).

Although the SMAD pathway is considered to be the central conduit for signals from the TGF- $\beta$ receptors, emerging evidence highlights the importance of non-SMAD pathways (75). NonSMAD molecules activated by TGF- $\beta$ include protein kinases (the MAPKs p38 and JNK, focal adhesion kinase [FAK], and TGF- $\beta$ activated kinase 1), lipid kinases (such as PI3K and its downstream target, AKT), and the calcium-dependent phosphatase calcineurin (Figure 4). Recent studies indicate novel roles for the tyrosine kinase c-ABL (76) and early growth response 1 (77) in mediating the stimulation of profibrotic responses induced by TGF- $\beta$ in fibroblasts. These novel non-SMAD pathways interact with each other and with SMAD proteins in complex, cell lineage-specific signaling networks.

Molecular effectors offibrosis: cytokines, growth factors, and chemokines. In addition to TGF- $\beta$, an expanding list of cytokines, growth factors, and chemokines that regulate mesenchymal cell function has been found to be overexpressed or abnormally regulated in patients with SSc. These soluble factors contribute to the pathogenesis of fibrosis and represent attractive potential targets for therapy. CTGF is a cysteine-rich modular protein belonging to the Cyr61/CTGF/NOV (CCN) family of matricellular growth factors, all of which function as adaptor molecules connecting the cell surface to the ECM (78). The CCN proteins have adhesive abilities that control cell attachment and migration, modulate the activi- 


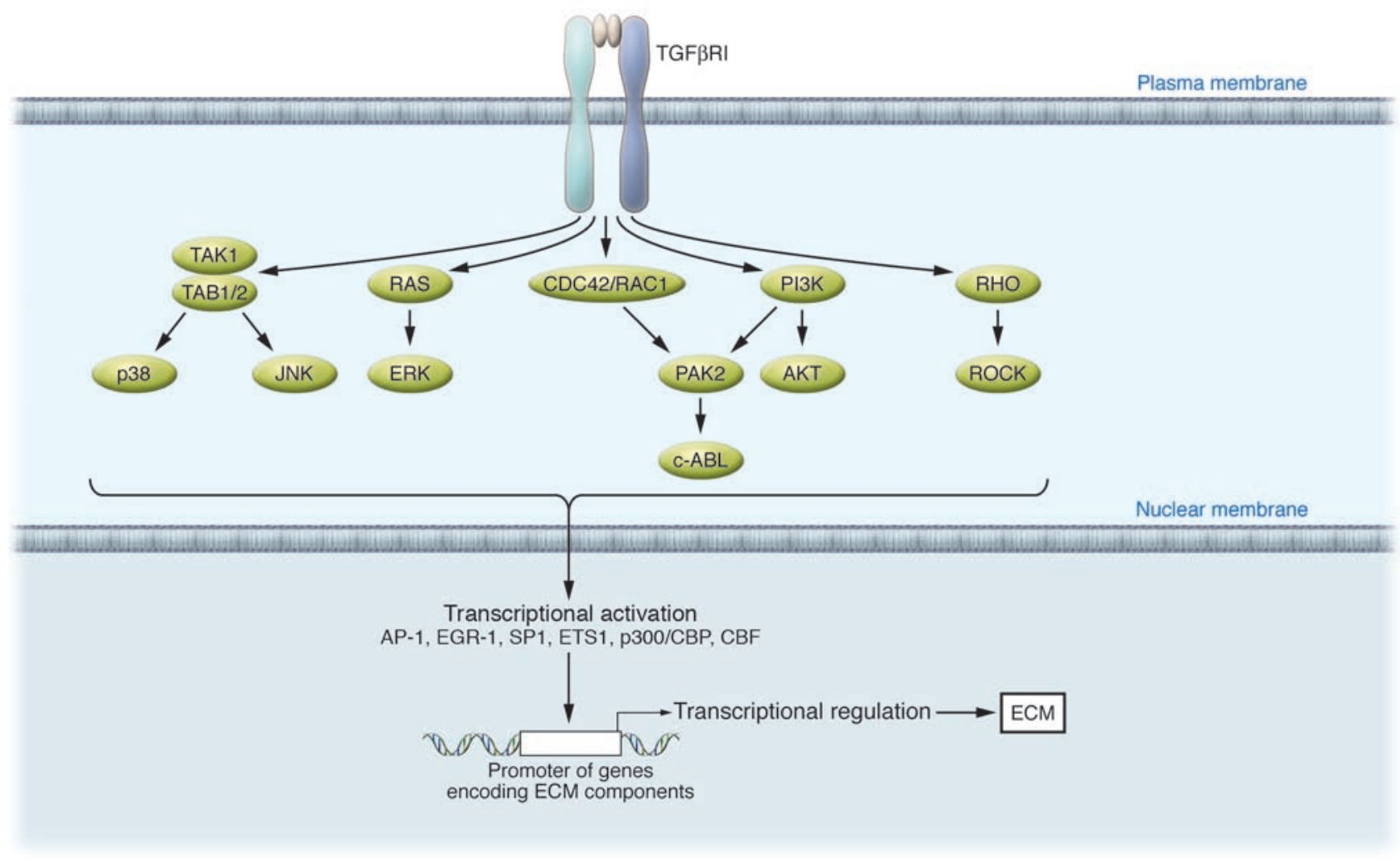

Figure 4

TGF- $\beta$ signaling through non-SMAD pathways. Receptor activation by TGF- $\beta$ can cause activation of non-SMAD pathways involved in regulating cell proliferation, cytoskeletal rearrangement, ECM synthesis, and apoptosis. Activation of intracellular protein and lipid kinase cascades results in activation of DNA-binding transcription factors and regulation of gene expression. These signal transdution pathways might converge on or interact with the canonical SMAD pathway or operate completely independent of SMAD pathways. AP-1, acivator protein 1; EGR-1, early growth response 1; PAK2, p21-activated kinase 2; ROCK, Rho-associated, coiled-coil containing protein kinase 1; TAB1/2, TAK1-binding protein 1/2; TAK1, TGF- $\beta$ activated kinase 1.

ties of TGF- $\beta$ and other cytokines, and regulate cell differentiation, proliferation, apoptosis, and ECM synthesis (78). Although expressed at only very low levels in normal tissues, expression of CTGF is induced by TGF- $\beta$ as well as ET- 1 and hypoxia (78). The levels of CTGF are markedly elevated in lesional tissues from patients with SSc (79) and in mouse models of scleroderma (19). Because many activities of CTGF parallel those induced by TGF- $\beta$, it has been suggested that at least some TGF- $\beta$ responses are mediated through endogenous CTGF (78). The identity of the fibroblast receptor for CTGF and the mechanism of action underlying profibrotic responses elicited by this matricellular protein are still incompletely characterized. PDGF, which is produced by macrophages, endothelial cells, and fibroblasts in addition to platelets, is a potent mitogen and chemoattractant for fibroblasts and can induce them to synthesize collagen, fibronectin, and proteoglycans and to secrete TGF- $\beta 1$, monocyte chemoattractant protein 1 (MCP-1), and IL-6. The expression of PDGF and its receptors is elevated on SSc fibroblasts and in lesional tissues (80) and in bronchoalveolar lavage fluid of SSc patients (81). Autoantibodies specific for the PDGF receptor can be detected in serum from patients with SSc (51). These antibodies have been shown to induce activation of normal fibroblasts in vitro through PDGF receptor-mediated activation of the intracellular Ha-Ras-ERK1/2 cascade and generation of ROS (51).
The cytokines IL-4 and IL-13 have major roles in the pathogenesis of Th2 cell-mediated diseases such as asthma and in the pathogenesis of fibrotic disorders (40). In normal fibroblasts, IL-4 stimulates proliferation, chemotaxis, and collagen synthesis and enhances the production of TGF- $\beta$ and CTGF (82). Levels of IL-4 are elevated in the sera of patients with SSc (83), and the number of IL-4-producing T cells is increased in their peripheral blood $(84,85)$. Expression of IL-4 protein and mRNA is markedly elevated in SSc lesional skin and cultured fibroblasts (86). The profibrotic activities of IL-13 involve both direct fibroblast activation and indirect mechanisms due to stimulation of TGF- $\beta$ $(87,88)$. Although levels of IL-13 are elevated in the serum of patients with SSc, its role in inducing and maintaining tissue fibrosis in SSc remains to be determined. Chemokines have a broad range of cellular targets and biological activities and are increasingly implicated in fibrosis (60). In vitro, MCP-1 stimulates collagen production directly or indirectly through the induction of endogenous TGF- $\beta$ and IL-4 (89). Levels of MCP-1 and of multiple other chemokines are elevated in the serum and bronchoalveolar lavage fluid from patients with SSc and correlate with the severity of fibrosis $(90,91)$. The expression of MCP-1 and MCP-3 and of their receptors is markedly elevated in lesional skin and cultured fibroblasts from patients with SSc, particularly in early-stage disease $(92,93)$. 
Endogenous mechanisms for attenuating the fibrotic response. To avoid excessive scarring following injury, redundant biological mechanisms have evolved to suppress ECM synthesis and fibroblast proliferation and differentiation and thereby slow the fibrotic process. Appropriate temporospatial utilization of these mechanisms allows repair of damaged tissue without the development of fibrosis. The prototypic Th 1 cytokine IFN- $\gamma$ suppresses the expression of the genes encoding the collagen proteins and abrogates the stimulatory effects of TGF- $\beta(94,95)$. IFN- $\gamma$ is also a potent inhibitor of fibroblast proliferation, ECM contraction, and fibroblast transdifferentiation to myofibroblasts (60). It has been shown that IFN- $\gamma$ suppresses fibrotic responses in vivo and in vitro (96) and therefore might have a physiological function as an endogenous natural antifibrotic mediator. Although some studies suggest that IL-10 (alone or in combination with IFN- $\gamma$ ) also functions as a repressor of the fibrotic process (97), the role of IL-10 in SSc remains to be clarified.

Fibroblasts are equipped with endogenous molecules that can suppress the stimulation of ECM gene expression. For example, by blocking SMAD-mediated TGF- $\beta$ signal transduction, SMAD7 limits the intensity and duration of the TGF- $\beta$ response and prevents prolonged stimulation of collagen synthesis by normal fibroblasts (98). Impaired SMAD7 expression or function has been demonstrated in SSc fibroblasts (99). Additional molecules that function as intrinsic repressors of basal or inducible collagen synthesis include the transcription factors SP3, FLI-1, p53, RAS, and the nuclear hormone receptor PPAR $\gamma$ (100-103). Diminished expression or function of these endogenous inhibitors, or their impaired responsiveness to extracellular ligands, could contribute to excessive and sustained ECM upregulation in fibrosis.

SSc fibroblasts: autonomously activated effector cells in fibrosis. Over 3 decades ago, E.C. LeRoy demonstrated that fibroblasts explanted from lesional skin or the fibrotic lungs of patients with SSc displayed an abnormal activated phenotype that persisted for several passages in vitro (104). This seminal observation focused attention on the pivotal role of the fibroblast in the pathogenesis of fibrosis and spawned extensive research into the underlying mechanisms (105). Persistent fibroblast activation in the absence of the fibrotic tissue milieu, confirmed more recently by DNA microarray studies $(52,106,107)$, indicates autonomous, signal-independent alterations in cell function. The SSc phenotype is characterized by enhanced ECM synthesis, constitutive secretion of cytokines and chemokines, and increased expression of cell surface receptors for fibrogenic signaling mediators (60). Moreover, SSc fibroblasts show evidence of myofibroblast transdifferentiation, due in part to constitutive activation of FAK (108). Elevated expression of the prosurvival factors BCL2 and AKT in fibroblasts from patients with SSc might account for their relative resistance to apoptosis (109-111). Because most of the SSc fibroblast characteristics can be induced in normal fibroblasts by incubation with TGF- $\beta$, it has been proposed that the SSc phenotype is due to autocrine TGF- $\beta$ signaling (60). The levels of receptors for TGF- $\beta$ are elevated on $\mathrm{SSc}$ fibroblasts, permitting them to mount a robust response to endogenously produced TGF- $\beta$ or to subthreshold levels of exogenous TGF- $\beta$ in their environment $(112,113)$. Furthermore, thrombospondin and $\alpha_{v} \beta_{3}$ integrins, both of which can mediate latent TGF- $\beta$ activation, are elevated on SSc fibroblasts $(114,115)$. Consistent with the autocrine TGF- $\beta$ hypothesis, SSc fibroblasts show evidence of ligand-independent intracellular TGF- $\beta$ signaling, with elevated expression and nuclear accumulation of acti- vated SMAD3 $(99,116)$ and its constitutive interaction with the p300/CBP coactivator $(117,118)$. Other studies have demonstrated defective expression of function of endogenous suppressors of TGF- $\beta$ signaling such as FLI-1 and $\operatorname{SMAD7}(27,98,119)$, and of PPAR $\gamma$ (J. Varga and M. Whitfield, unpublished observations).

However, fibroblast activation mediated by an autocrine TGF- $\beta$ SMAD signaling pathway cannot fully account for all of the phenotypic hallmarks of SSc fibroblasts, such as constitutive production of CTGF or ET-1 (120). Furthermore, small molecule inhibitors of TGFßRI-dependent SMAD signaling fail to fully normalize SSc fibroblasts in vitro $(113,121,122)$. These recent observations therefore imply that SMAD-independent TGF- $\beta$ signaling mechanisms, TGF- $\beta$-independent activation events, or both also have a role in inducing or maintaining the SSc phenotype. The autonomous phenotype of SSc fibroblasts might also result from altered integrin signaling from the surrounding ECM (123). Recent evidence suggests that epigenetic regulation in SSc fibroblasts might contribute to their persistent dysfunction (119). For example, the gene encoding FLI-1, an important negative regulator of collagen synthesis, seems to be constitutively silenced in SSc fibroblasts through a mechanism that involves DNA methylation or chromatin histone deacetylation (119). Silencing the expression of this negative regulator is associated with increased collagen synthesis (119).

\section{Conclusions and perspectives}

Vascular injury and damage, along with autoimmunity and inflammation, are prominent early manifestations of SSc that precede the onset of fibrosis and contribute to its pathogenesis in poorly understood ways. Vascular damage and tissue fibrosis are widespread in SSc and largely account for the protean clinical manifestations and substantial morbidity and mortality. Current therapies such as cyclophosphamide, azathioprine, mycophenolate, D-penicillamine, and methotrexate are primarily immunomodulatory in nature. These agents have shown little or no effect on reversing fibrosis or slowing its progression or in altering the natural progression of the disease. Effective therapy will require directly targeting the fibrotic process and will necessitate an improved understanding of the roles of individual cell types and their products in the development of fibrosis. Despite substantial progress during the past decade in uncovering the molecular and cellular mechanisms underlying pathological fibrogenesis, translation of basic research findings into more effective management of patients with SSc has been slow. To identify novel therapeutic targets, additional studies are necessary to delineate the intracellular signaling pathways regulating the physiologic expression of ECM genes and their dysregulation in SSc as well as the factors governing mesenchymal cell transdifferentiation into activated myofibroblasts and accumulation of circulation-derived progenitors in the lesional tissues during the fibrotic process. Genetic analysis to identify determinants that influence disease susceptibility and clinical phenotypes will also be needed. Clinical evaluation of targeted drugs and interventions for SSc is critically dependent on the availability of simple and reliable biomarkers for assessing disease severity and progression and therapeutic response. In addition to novel therapies that block key mediators in fibrosis, such as TGF- $\beta$, CTGF, ET-1, and chemokines, or that inhibit the activities or interactions of intracellular signaling molecules such as TGF $\beta$ RI, FAK, and p300/CBP, several drugs already in use for the treatment of other conditions might turn out to have substantial unexpected utility in SSc. Such drugs include the c-ABL kinase inhibitor ima- 
tinib (used to treat chronic myelogenous leukemia), statins (used to treat hyperlipidemia and cardiovascular disease), the angiotensin II receptor blocker losartan (used to treat hypertension), and the insulin-sensitizing thiazolidinedione PPAR $\gamma$ agonists (used to treat type II diabetes). Each of these agents has been shown to have vasculoprotective, antiinflammatory, and antifibrotic activities over and above their kinase-blocking, lipid-lowering, hypotensive, and insulin-sensitizing activities, respectively, and therefore should undergo rigorous evaluation for the treatment of SSc.

\section{Acknowledgments}

This work was supported by grants from the NIH (AR42309 and AR49025).

Address correspondence to: John Varga, Division of Rheumatology, Northwestern University Feinberg School of Medicine, McGaw Pavilion M-300, 240 East Huron Street, Chicago, Illinois 60611, USA. Phone: (312) 503-0377; Fax: (312) 503-0994; E-mail: j-varga@northwestern.edu.
1. Abraham, D.J., and Varga, J. 2005. Scleroderma: from cell and molecular mechanisms to disease models. Trends Immunol. 26:587-595.

2. LeRoy, E.C., and Medsger, T.A., Jr. 2001. Criteria for the classification of early systemic sclerosis. J. Rheumatol. 28:1573-1576.

3. Mayes, M.D., et al. 2003. Prevalence, incidence, survival, and disease characteristics of systemic sclerosis in a large US population. Arthritis Rheum. 48:2246-2255.

4. Feghali-Bostwick, C., Medsger, T.A., Jr., and Wright, T.M. 2003. Analysis of systemic sclerosis in twins reveals low concordance for disease and high concordance for the presence of antinuclear antibodies. Arthritis Rheum. 48:1956-1963.

5. Arnett, F.C., et al. 2001. Familial occurrence frequencies and relative risks for systemic sclerosis (scleroderma) in three United States cohorts. Arthritis Rheum. 44:1359-1362.

6. Pandey, J.P., and LeRoy, E.C. 1998. Human cytomegalovirus and the vasculopathies of autoimmune diseases (especially scleroderma), allograft rejection, and coronary restenosis. Arthritis Rheum. 41:10-15.

7. Nietert, P.J., and Silver, R.M. 2000. Systemic sclerosis: environmental and occupational risk factors. Curr. Opin. Rheumatol. 12:520-526.

8. Namboodiri, A.M., Rocca, K.M., and Pandey, J.P. 2004. IgG antibodies to human cytomegalovirus late protein UL94 in patients with systemic sclerosis. Autoimmunity. 37:241-244.

9. Lunardi, C., et al. 2006. Antibodies against human cytomegalovirus in the pathogenesis of systemic sclerosis: a gene array approach. PLoS Med. 3:e2.

10. Lunardi, C., et al. 2000. Systemic sclerosis immunoglobulin $\mathrm{G}$ autoantibodies bind the human cytomegalovirus late protein UL94 and induce apoptosis in human endothelial cells. Nat. Med. 6:1183-1186.

11. Inkinen, K., et al. 2005. Cytomegalovirus enhance expression of growth factors during the development of chronic allograft nephropathy in rats. Transpl. Int. 18:743-749.

12. Green, M.C., Sweet, H.O., and Bunker, L.E. 1976. Tight-skin, a new mutation of the mouse causing excessive growth of connective tissue and skeleton. Am. J. Pathol. 82:493-512.

13. Baxter, R.M., Crowell, T.P., McCrann, M.E., Frew, E.M., and Gardner, H. 2005. Analysis of the tight skin (Tsk1/+) mouse as a model for testing antifibrotic agents. Lab. Invest. 85:1199-1209.

14. Siracusa, L.D., et al. 1996. A tandem duplication within the fibrillin 1 gene is associated with the mouse tight skin mutation. Genome Res. 6:300-313.

15. Habashi, J.P., et al. 2006. Losartan, an AT1 antagonist, prevents aortic aneurysm in a mouse model of Marfan syndrome. Science. 312:117-121.

16. Isogai, Z., et al. 2003. Latent transforming growth factor-beta-binding protein 1 interacts with fibrillin and is a microfibril-associated protein. J. Biol. Chem. 278:2750-2757.

17. Yamamoto, T., et al. 1999. Animal model of sclerotic skin. I: Local injections of bleomycin induce sclerotic skin mimicking scleroderma. J. Invest. Dermatol. 112:456-462.
18. Takagawa, S., et al. 2003. Sustained activation of fibroblast transforming growth factor-beta/Smad signaling in a murine model of SSc. J. Invest. Dermatol. 121:41-50.

19. Lakos, G., et al. 2004. Targeted disruption of TGFbeta/Smad3 signaling modulates skin fibrosis in a mouse model of scleroderma. Am. J. Pathol. 165:203-217.

20. Ferreira, A.M., et al. 2006. Diminished induction of skin fibrosis in mice with MCP-1 deficiency. J. Invest. Dermatol. 126:1900-1908.

21. Zhang, Y., McCormick, L.L., Desai, S.R., Wu, C., and Gilliam, A.C. 2002. Murine sclerodermatous graftversus-host disease, a model for human scleroderma: cutaneous cytokines, chemokines, and immune cell activation. J. Immunol. 168:3088-3098.

22. Ruzek, M.C., Jha, S., Ledbetter, S., Richards, S.M., and Garman, R.D. 2004. A modified model of graft-versus-host-induced systemic sclerosis (scleroderma) exhibits all major aspects of the human disease. Arthritis Rheum. 50:1319-1331.

23. Samuel, C.S., et al. 2005. The relaxin gene knockout mouse: a model of progressive scleroderma. J. Invest. Dermatol. 125:692-699.

24. Razani, B., et al. 2001. Caveolin-1 null mice are viable but show evidence of hyperproliferative and vascular abnormalities. J. Biol. Chem. 276:38121-38138.

25. Hagood, J.S., et al. 2005. Loss of fibroblast Thy-1 expression correlates with lung fibrogenesis. Am.J. Pathol. 167:365-379.

26. Kubo, M., et al. 2003. Persistent down-regulation of Fli1, a suppressor of collagen transcription, in fibrotic scleroderma skin. Am. J. Pathol. 163:571-581.

27. Denton, C.P., et al. 2005. Activation of key profibrotic mechanisms in transgenic fibroblasts expressing kinase-deficient type II Transforming growth factor-\{beta\} receptor. J. Biol. Chem. 280:16053-16065.

28. Kahaleh, M.B., Sherer, G.K., and LeRoy, E.C. 1979. Endothelial injury in scleroderma. J. Exp. Med. 149:1326-1335.

29. Kahaleh, M.B. 2004. Raynaud phenomenon and the vascular disease in scleroderma. Curr. Opin. Rheumatol. 16:718-722.

30. Cerinic, M.M., et al. 2003. Blood coagulation, fibrinolysis, and markers of endothelial dysfunction in systemic sclerosis. Semin. Arthritis Rheum. 32:285-295.

31. Vancheeswaran, R., Azam, A., Black, C., and Dashwood, M.R. 1994. Localization of endothelin-1 and its binding sites in scleroderma skin. J. Rheumatol. 21:1268-1276

32. Cambrey, A.D., et al. 1994. Increased levels of endothelin-1 in bronchoalveolar lavage fluid from patients with systemic sclerosis contribute to fibroblast mitogenic activity in vitro. Am. J. Respir. Cell Mol. Biol. 11:439-445.

33. Flavahan, N.A., Flavahan, S., Mitra, S., and Chotani, M.A. 2003. The vasculopathy of Raynaud's phenomenon and scleroderma. Rheum. Dis. Clin. North Am. 29:275-291.

34. Distler, O., et al. 2004. Uncontrolled expression of vascular endothelial growth factor and its receptors leads to insufficient skin angiogenesis in patients with systemic sclerosis. Circ. Res. 95:109-116.
35. Davies, C.A., Jeziorska, M., Freemont, A.J., and Herrick, A.L. 2006. The differential expression of VEGF, VEGFR-2, and GLUT-1 proteins in disease subtypes of systemic sclerosis. Hum. Pathol. 37:190-197.

36. Kuwana, M., Okazaki, Y., Yasuoka, H., Kawakami, Y., and Ikeda, Y. 2004. Defective vasculogenesis in systemic sclerosis. Lancet. 364:603-610.

37. Del Papa, N.D., et al. 2006. Bone marrow endothelial progenitors are defective in systemic sclerosis. Arthritis Rheum. 54:2605-2615.

38. Artlett, C.M. 2005. Immunology of systemic sclerosis. Front. Biosci. 10:1707-1719.

39. Sakkas, L.I., et al. 2002. Oligoclonal T cell expansion in the skin of patients with systemic sclerosis. J. Immunol. 168:3649-3659.

40. Wynn, T.A. 2004. Fibrotic disease and the T(H)1/ $\mathrm{T}(\mathrm{H}) 2$ paradigm. Nat. Rev. Immunol. 4:583-594.

41. Wangoo, A., et al. 2001. Contribution of Th1 and Th2 cells to protection and pathology in experimental models of granulomatous lung disease. J. Immunol. 166:3432-3439.

42. Lakos, G., Melichian, D., Wu, M., and Varga, J. 2007. Increased bleomycin-induced skin fibrosis in mice lacking the Th1-specific transcription factor T-bet. Pathobiology. In press.

43. Tan, F.K., et al. 2006. Signatures of differentially regulated interferon gene expression and vasculotrophism in the peripheral blood cells of systemic sclerosis patients. Rheumatology (Oxford). 45:694-702.

44. Mavalia, C., et al. 1997. Type 2 helper T-cell predominance and high CD30 expression in systemic sclerosis. Am. J. Pathol. 151:1751-1758.

45. Atamas, S.P., et al. 1999. Production of type 2 cytokines by CD8+ lung cells is associated with greater decline in pulmonary function in patients with systemic sclerosis. Arthritis Rheum. 42:1168-1178.

46. Rottoli, P., et al. 2005. Cytokine profile and proteome analysis in bronchoalveolar lavage of patients with sarcoidosis, pulmonary fibrosis associated with systemic sclerosis and idiopathic pulmonary fibrosis. Proteomics. 5:1423-1430.

47. Hu, P.Q., Fertig, N., Medsger, T.A., Jr., and Wright, T.M. 2003. Correlation of serum anti-DNA topoisomerase I antibody levels with disease severity and activity in systemic sclerosis. Arthritis Rheum. 48:1363-1373.

48. Harris, M.L., and Rosen, A. 2003. Autoimmunity in scleroderma: the origin, pathogenetic role, and clinical significance of autoantibodies. Curr. Opin. Rheumatol. 15:778-784.

49. Carvalho, D., Savage, C.O., Black, C.M., and Pearson, J.D. 1996. IgG antiendothelial cell autoantibodies from scleroderma patients induce leukocyte adhesion to human vascular endothelial cells in vitro. Induction of adhesion molecule expression and involvement of endothelium-derived cytokines. J. Clin. Invest. 97:111-119.

50. Henault, J., Robitaille, G., Senecal, J.L., and Raymond, Y. 2006. DNA topoisomerase I binding to fibroblasts induces monocyte adhesion and activation in the presence of anti-topoisomerase I autoantibodies from systemic sclerosis patients. Arthritis Rheum. 54:963-973.

51. Baroni, S.S., et al. 2006. Stimulatory autoantibod- 
ies to the PDGF receptor in systemic sclerosis. N. Engl. J. Med. 354:2667-2676.

52. Whitfield, M.L., et al. 2003. Systemic and cell typespecific gene expression patterns in scleroderma skin. Proc. Natl. Acad. Sci. U. S. A. 100:12319-12324.

53. Sato, S., Fujimoto, M., Hasegawa, M., and Takehara, K. 2004. Altered blood B lymphocyte homeostasis in systemic sclerosis: expanded naive B cells and diminished but activated memory B cells. Arthritis Rheum. 50:1918-1927.

54. Sato, S., et al. 2000. Quantitative genetic variation in CD19 expression correlates with autoimmunity. J. Immunol. 165:6635-6643.

55. Hasegawa, M., et al. 2006. B-lymphocyte depletion reduces skin fibrosis and autoimmunity in the tight-skin mouse model for systemic sclerosis. Am. J. Pathol. 169:954-966.

56. Matsushita, T., et al. 2006. Elevated serum BAFF levels in patients with systemic sclerosis: enhanced BAFF signaling in systemic sclerosis B lymphocytes. Arthritis Rheum. 54:192-201.

57. Denton, C.P., Black, C.M., and Abraham, D.J. 2006 Mechanisms and consequences of fibrosis in systemic sclerosis. Nat. Clin. Pract. Rheumatol. 2:134-144.

58. Varga, J., and Bashey, R.I. 1995. Regulation of connective tissue synthesis in systemic sclerosis. Int Rev. Immunol. 12:187-199.

59. Ramirez, F., Tanaka, S., and Bou-Gharios, G. 2006. Transcriptional regulation of the human alpha 2(I) collagen gene (COL1A2), an informative model system to study fibrotic diseases. Matrix Biol. 25:365-372

60. Pannu, J., and Trojanowska, M. 2004. Recent advances in fibroblast signaling and biology in scleroderma. Curr. Opin. Rheumatol. 16:739-745.

61. Abraham, D.J., Exckes, B., Rajkumar, V., and Krieg, T. 2007. New developments in fibroblast and myofibroblast biology: implications for fibrosis and scleroderma. Curr. Rheumatol. Rep. In press.

62. Chang, H.Y., et al. 2002. Diversity, topographic differentiation, and positional memory in human fibroblasts. Proc. Natl. Acad. Sci. U. S. A. 99:12877-12882.

63. Desmouliere, A., Chaponnier, C., and Gabbiani, G. 2005. Tissue repair, contraction, and the myofibroblast. Wound Repair Regen. 13:7-12.

64. Jelaska, A., Arakawa, M., Broketa, G., and Korn, J.H. 1996. Heterogeneity of collagen synthesis in normal and systemic sclerosis skin fibroblasts. Increased proportion of high collagen-producing cells in systemic sclerosis fibroblasts. Artbritis Rheum. 39:1338-1346.

65. Rajkumar, V.S., et al. 2005. Shared expression of phenotypic markers in systemic sclerosis indicates a convergence of pericytes and fibroblasts to a myofibroblast lineage in fibrosis. Arthritis Res. Ther. 7:1113-1123

66 Yamagishi, S., and Imaizumi, T. 2005. Pericyte biology and diseases. Int. J. Tissue React. 27:125-135.

67. Kalluri, R., and Neilson, E.G. 2003. Epithelialmesenchymal transition and its implications for fibrosis. J. Clin. Invest. 112:1776-1784. doi:10.1172/ JCI200320530.

68. Abe, R., Donnelly, S.C., Peng, T., Bucala, R., and Metz, C.N. 2001. Peripheral blood fibrocytes: differentiation pathway and migration to wound sites. J. Immunol. 166:7556-7562.

69. Cipriani, P., et al. 2006. Differential expression of stromal cell-derived factor 1 and its receptor CXCR4 in the skin and endothelial cells of systemic sclerosis patients: Pathogenetic implications. Arthritis Rheum. 54:3022-3033.

70. Phillips, R.J. 2004. Circulating fibrocytes traffic to the lungs in response to CXCL12 and mediate fibrosis. J. Clin. Invest. 114:438-446. doi:10.1172/ JCI200420997.

71. Kuwana, M., et al. 2003. Human circulating CD14+ monocytes as a source of progenitors that exhibit mesenchymal cell differentiation. J. Leukoc. Biol.
74:833-845.

72. Blobe, G.C., Schiemann, W.P., and Lodish, H.F. 2000. Role of transforming growth factor beta in human disease. N. Engl. J. Med. 342:1350-1358.

73. Annes, J.P., Munger, J.S., and Rifkin, D.B. 2003. Making sense of latent TGFbeta activation. J. Cell Sci. 116:217-224.

74. Massague, J., and Gomis, R.R. 2006. The logic of TGFbeta signaling. FEBS Lett. 580:2811-2820.

75. Moustakas, A., and Heldin, C.H. 2005. Non-Smad TGF-beta signals. J. Cell Sci. 118:3573-3584.

76. Daniels, C.E., et al. 2004. Imatinib mesylate inhibits the profibrogenic activity of TGF-beta and prevents bleomycin-mediated lung fibrosis. J. Clin. Invest. 114:1308-1316. doi:10.1172/JCI200419603.

77. Chen, S.J., et al. 2006. The early-immediate gene EGR-1 is induced by transforming growth factorbeta and mediates stimulation of collagen gene expression. J. Biol. Chem. 281:21183-21197.

78. Leask, A., and Abraham, D.J. 2006. All in the CCN family: essential matricellular signaling modulators emerge from the bunker. J. Cell Sci. 119:4803-4810.

79. Igarashi, A., et al. 1996. Connective tissue growth factor gene expression in tissue sections from localized scleroderma, keloid, and other fibrotic skin disorders. J. Invest. Dermatol. 106:729-733.

80. Gay, S., Jones, R.E., Jr., Huang, G.Q., and Gay, R.E. 1989. Immunohistologic demonstration of platelet-derived growth factor (PDGF) and sis-oncogene expression in scleroderma. J. Invest. Dermatol. 92:301-303.

81. Ludwicka, A., et al. 1995. Elevated levels of platelet derived growth factor and transforming growth factor-beta 1 in bronchoalveolar lavage fluid from patients with scleroderma. J. Rheumatol. 22:1876-1883

82. Postlethwaite, A.E., Holness, M.A., Katai, H., and Raghow, R. 1992. Human fibroblasts synthesize elevated levels of extracellular matrix proteins in response to interleukin 4. J. Clin. Invest. 90:1479-1485.

83. Hasegawa, M., Fujimoto, M., Kikuchi, K., and Takehara, K. 1997. Elevated serum levels of interleukin 4 (IL-4), IL-10, and IL-13 in patients with systemic sclerosis. J. Rheumatol. 24:328-332.

84. Sakkas, L.I., et al. 1999. Increased levels of alternatively spliced interleukin 4 (IL-4delta2) transcripts in peripheral blood mononuclear cellsfrom patients with systemic sclerosis. Clin. Diagn. Lab. Immunol. 6:660-664.

85. Tsuji-Yamada, J., Nakazawa, M., Minami, M., and Sasaki, T. 2001. Increased frequency of interleukin 4 producing $\mathrm{CD} 4+$ and $\mathrm{CD} 8+$ cells in peripheral blood from patients with systemic sclerosis. J. Rhew matol. 28:1252-1258.

86. Salmon-Ehr, V. 1996. Expression of interleukin-4 in scleroderma skin specimens and scleroderma fibroblast cultures. Potential role in fibrosis. Arch Dermatol. 132:802-806.

87. Jinnin, M., Ihn, H., Yamane, K., and Tamaki, K. 2004. Interleukin-13 stimulates the transcription of the human alpha2(I) collagen gene in human dermal fibroblasts. J. Biol. Chem. 279:41783-41791.

88. Kaviratne, M., et al. 2004. IL-13 activates a mechanism of tissue fibrosis that is completely TGF-beta independent. J. Immunol. 173:4020-4029.

89. Distler, J.H., et al. 2006. Monocyte chemoattractant protein 1 released from glycosaminoglycans mediates its profibrotic effects in systemic sclerosis via the release of interleukin-4 from T cells. Arthritis Rheum. 54:214-225.

90. Galindo, M., et al. 2001. Chemokine expression by systemic sclerosis fibroblasts: abnormal regulation of monocyte chemoattractant protein 1 expression. Arthritis Rheum. 44:1382-1386.

91. Kodera, M., et al. 2005. Serum pulmonary and activation-regulated chemokine/CCL18 levels in patients with systemic sclerosis: a sensitive indicator of active pulmonary fibrosis. Arthritis Rheum.
52:2889-2896.

92. Carulli, M.T., et al. 2005. Chemokine receptor CCR2 expression by systemic sclerosis fibroblasts: evidence for autocrine regulation of myofibroblast differentiation. Arthritis Rheum. 52:3772-3782.

93. Ong, V.H., et al. 2003. Monocyte chemoattractant protein 3 as a mediator of fibrosis: Overexpression in systemic sclerosis and the type 1 tight-skin mouse. Arthritis Rheum. 48:1979-1991.

94. Jimenez, S.A., Freundlich, B., and Rosenbloom, J. 1984. Selective inhibition of human diploid fibroblast collagen synthesis by interferons. J. Clin. Invest. 74:1112-1116.

95. Ghosh, A.K., et al. 2001. Antagonistic regulation of type I collagen gene expression by interferongamma and transforming growth factor-beta. Integration at the level of p300/CBP transcriptional coactivators. J. Biol. Chem. 276:11041-11048.

96 Varga, J. 1997. Recombinant cytokine treatment for scleroderma. Can the antifibrotic potential of interferon-gamma be realized clinically? Arch. Dermatol. 133:637-642.

97. Arai, T., et al. 2000. Introduction of the interleukin-10 gene into mice inhibited bleomycin-induced lung injury in vivo. Am. J. Physiol. Lung Cell. Mol. Physiol. 278:L914-L922.

98. Chen, S.J., et al. 1999. Stimulation of type I collagen transcription in human skin fibroblasts by TGF-beta: involvement of Smad 3. J. Invest. Derma tol. 112:49-57.

99. Dong, C., et al. 2002. Deficient Smad7 expression: a putative molecular defect in scleroderma. Proc. Natl. Acad. Sci. U. S. A. 99:3908-3913.

100.Chen, S.J., Artlett, C.M., Jimenez, S.A., and Varga, J. 1998. Modulation of human alpha1(I) procollagen gene activity by interaction with $\mathrm{Sp} 1$ and $\mathrm{Sp} 3$ transcription factors in vitro. Gene. 215:101-110.

101.Czuwara-Ladykowska, J., Shirasaki, F., Jackers, P., Watson, D.K., and Trojanowska, M. 2001. Fli-1 inhibits collagen type I production in dermal fibroblasts via an Sp1-dependent pathway. J. Biol. Chem. 276:20839-20848.

102.Ghosh, A.K., Bhattacharyya, S., and Varga, J. 2004. The tumor suppressor $\mathrm{p} 53$ abrogates Smad-dependent collagen gene induction in mesenchymal cells. J. Biol. Chem. 279:47455-47463.

103. Ghosh, A.K., et al. 2004. Disruption of transforming growth factor beta signaling and profibrotic responses in normal skin fibroblasts by peroxisome proliferator-activated receptor gamma. Arthritis Rheum. 50:1305-1318.

104.LeRoy, E.C. 1974. Increased collagen synthesis by scleroderma skin fibroblasts in vitro: a possible defect in the regulation or activation of the scleroderma fibroblast. J. Clin. Invest. 54:880-889.

105. Trojanowska, M. 2004. What did we learn by studying scleroderma fibroblasts? Clin. Exp. Rheumatol. 22(Suppl. 3):S59-S63.

106.Gardner, H., et al. 2006. Gene profiling of scleroderma skin reveals robust signatures of disease that are imperfectly reflected in the transcript profiles of explanted fibroblasts. Arthritis Rheum. 54:1961-1973.

107. Tan, F.K., et al. 2005. Classification analysis of the transcriptosome of nonlesional cultured dermal fibroblasts from systemic sclerosis patients with early disease. Arthritis Rheum. 52:865-876.

108. Mimura, Y., et al. 2005. Constitutive phosphorylation of focal adhesion kinase is involved in the myofibroblast differentiation of SSc fibroblasts. J. Invest. Dermatol. 124:886-892.

109.Santiago, B., Galindo, M., Rivero, M., and Pablos, J.L. 2001. Decreased susceptibility to Fas-induced apoptosis of systemic sclerosis dermal fibroblasts. Arthritis Rheum. 44:1667-1676.

110.Jun, J.B., et al. 2005. SSc fibroblasts demonstrate enhanced activation of Akt (protein kinase B) in situ. J. Invest. Dermatol. 124:298-303. 
111.Jelaska, A., and Korn, J.H. 2000. Role of apoptosis and transforming growth factor beta 1 in fibroblast selection and activation in systemic sclerosis. Arthritis Rheum. 43:2230-2239.

112. Kawakami, T., et al. 1998. Increased expression of TGF-beta receptors by scleroderma fibroblasts: evidence for contribution of autocrine TGF-beta signaling to scleroderma phenotype. J. Invest. Dermatol. 110:47-51.

113.Pannu, J., Gardner, H., Shearstone, J.R., Smith, E., and Trojanowska, M. 2006. Increased levels of transforming growth factor beta receptor type I and up-regulation of matrix gene program: A model of scleroderma. Arthritis Rheum. 54:3011-3021.

114. Mimura, Y., et al. 2005. Constitutive thrombospondin-1 overexpression contributes to autocrine TGF-beta signaling in cultured scleroderma fibroblasts. Am. J. Pathol. 166:1451-1463.

115.Asano, Y., et al. 2005. Involvement of alphavbeta5 integrin-mediated activation of latent transforming growth factor beta 1 in autocrine TGF beta signaling in systemic sclerosis fibroblasts. Arthritis Rheum. 52:2897-2905.

116.Mori, Y., Chen, S.J., and Varga, J. 2003. Expression and regulation of intracellular SMAD signaling in scleroderma skin fibroblasts. Arthritis Rheum. 48:1964-1978.

117. Bhattacharyya, S., et al. 2005. Fibroblast expression of the coactivator $\mathrm{p} 300$ governs the intensity of profibrotic response to transforming growth factor beta. Arthritis Rheum. 52:1248-1258.

118.Ihn, H., Yamane, K., Asano, Y., Jinnin, M., and Tamaki, K. 2006. Constitutively phosphorylated Smad3 interacts with Sp1 and p300 in scleroderma fibroblasts. Rheumatology (Oxford). 45:157-165.

119.Wang, Y., Fan, P.S., and Kahaleh, B. 2006. Association between enhanced type I collagen expression and epigenetic repression of the FLI1 gene in sclero- derma fibroblasts. Arthritis Rheum. 54:2271-2279.

120.Shi-Wen, X., et al. 2006. Constitutive ALK5-independent c-Jun $\mathrm{N}$-terminal kinase activation contributes to endothelin-1 overexpression in pulmonary fibrosis: evidence of an autocrine endothelin loop operating through the endothelin A and B receptors. Mol. Cell. Biol. 26:5518-5527.

121.Ishida, W., et al. 2006. Intracellular TGF-beta receptor blockade abrogates Smad-dependent fibroblast activation in vitro and in vivo. J. Invest. Dermatol. 126:1733-1744

122. Chen, Y., et al. 2006. Contribution of activin receptor-like kinase 5 (transforming growth factor beta receptor type I) signaling to the fibrotic phenotype of scleroderma fibroblasts. Arthritis Rheum. 54:1309-1316.

123.Eckes, B., et al. 2006. Mechanical Tension and Integrin alpha2beta1 Regulate Fibroblast Functions. J. Invest. Dermatol. 126(Suppl.):66-72. 